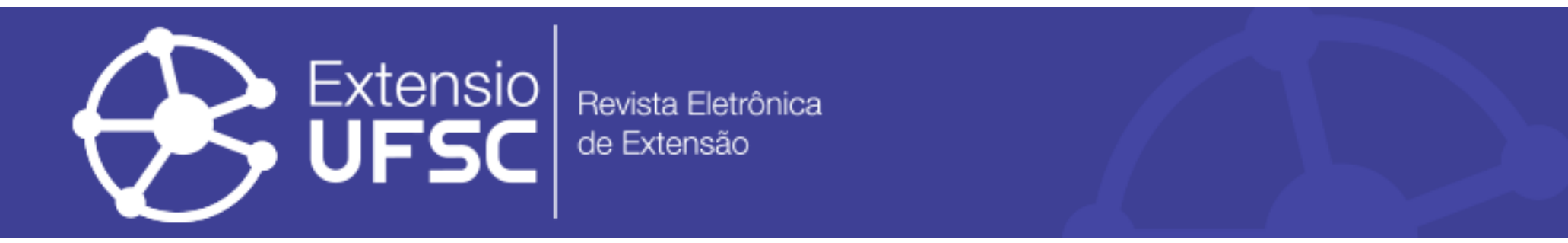

\title{
"MIL NAÇÕES MOLDARAM MINHA CARA"": O BRASIL, AS MIGRAÇÕES SUL-SUL E A EXTENSÃO EM RELAÇÕES INTERNACIONAIS
}

\author{
Karine de Souza Silva \\ Universidade Federal de Santa Catarina \\ karine.silva@ufsc.br \\ Daniel Ricardo Castelan \\ Universidade Federal de Santa Catarina \\ daniel.castelan@ufsc.br
}

\section{Resumo}

O objetivo deste artigo é apresentar o Projeto de Extensão "Cátedra Sérgio Vieira de Mello: Núcleo de Apoio a Imigrantes e Refugiados" da Universidade Federal de Santa Catarina, com vistas a contribuir com o debate sobre a extensão, nesse momento histórico de reconstituição dos laços entre ensino, pesquisa e extensão. Utilizando-se do método quali-quanti e das teorias Pós e Decoloniais, este trabalho aponta como principais resultados das práticas realizadas no período 20142019, a prestação de cerca de 30 mil atendimentos - em parceria com a Pastoral do Migrante, com o Centro de Referência no Atendimento a Imigrantes e Refugiados e com a Defensoria Pública da União - a pessoas de 62 nacionalidades, com preponderância dos sujeitos racializados do Sul Global. Trata-se de um projeto pioneiro que tem promovido encontros não-hieraquizados com a diferença, e tem contribuído para desenhar o perfil migratório de Santa Catarina no contexto da Migração Sul-Sul.

Palavras-chave: Extensão Universitária. Raça e Migrações Sul-Sul. Práticas Decoloniais.

\section{"A THOUSAND NATIONS SHAPED MY FACE": BRAZIL, SOUTH-SOUTH MIGRATIONS AND COMMUNITY ENGAGEMENT (OUTREACH) IN INTERNATIONAL RELATIONS}

\begin{abstract}
The objective of this article is to present the outreach project "Cátedra Sérgio Vieira de Mello: Núcleo de Apoio a Imigrantes e Refugiados" [Sérgio Vieira de Mello Chair: Immigrant and Refugee Support Center] of the Universidade Federal de Santa Catarina with the aim of contributing to the debate about university outreach in this historic moment when the ties between teaching, research and outreach are being reconstituted. Using the mixed-method approach and post- and decolonial theories, this paper presents the main results of the practices carried out between 2014 and 2019 : more than 30 thousand individual services - provided in partnership with the Migrant Ministry, the Center for Reference and Assistance for Immigrants and the Federal Public Defender's Office - to people of 62 nationalities, mostly racialized individuals of the Global South. This is a pioneer project that has promoted non-hierarchized encounters with difference and has contributed to draw up the migration profile of the state of Santa Catarina in the context of South-South Migration.

Keywords: University Outreach. Race and South-South Migrations. Decolonial Practices.

\section{"MIL NACIONES CONFORMARON MI CARA": BRASIL, MIGRACIÓN SUR-SUR Y EXTENSIÓN EN LAS RELACIONES INTERNACIONALES}

\section{Resumen}

El objetivo de este artículo es presentar el Proyecto de Extensión "Cátedra Sérgio Vieira de Mello: Centro de Apoyo a Inmigrantes y Refugiados" de la Universidad Federal de Santa Catarina, con miras a contribuir al debate sobre la extensión, en este momento histórico de reconstitución de lazos. enseñanza, investigación y extensión Utilizando el método qualiquanti y las teorías Post y Decolonial, este trabajo señala como los principales resultados de las prácticas llevadas a cabo en el período 2014-2019, la provisión de aproximadamente 30 mil asistencias, en colaboración con Pastoral do Migrante, con el Centro de Referencia para Asistencia a Inmigrantes y Refugiados y con la Oficina del Defensor Público de la Unión, a personas de 62 nacionalidades, con preponderancia de sujetos racializados del Sur Global. Jerarquizado con la diferencia, y ha contribuido a dibujar el perfil migratorio de Santa Catarina en el contexto de la migración Sur-Sur.

Palavras clave: Extensión Universitaria. Raza Sur-Sur y Migraciones. Prácticas Descoloniales.

${ }^{1} \mathrm{O}$ que se cala. Autor Douglas Germano. Artista Elsa Soares.

${ }^{2} \mathrm{O}$ que se cala. Written by Douglas Germano. Performed by Elsa Soares. 
"Mil nações moldaram minha cara": o Brasil, as migrações Sul-Sul e a extensão em Relações Internacionais

\section{INTRODUÇÃO}

No contexto atual das migrações internacionais, no qual se intensificam os deslocamentos Sul-Sul ${ }^{3}$, o Brasil tem figurado como locus privilegiado de recepção de diversos nacionais de países periféricos e semiperiféricos que, em muitos casos, têm fugido da miséria, de perseguições, de conflitos armados, ou mesmo aspiram a melhores condições de estudo, de trabalho e, enfim, de existência. Enquanto o Brasil na sua condição de nação emergente passou a se constituir como um polo de atração para os denominados novos imigrantes ${ }^{4}$, o Sul do país, na última década, tem figurado como a região que tem atraído o maior número de pessoas em situação de mobilidade. Isto advém, sobretudo, das possibilidades de incorporação no mercado de trabalho, que têm se revelados superiores às médias nacionais.

De fato, a partir de 2010 houve um incremento significativo nos índices da presença de imigrantes do Sul Global, em Santa Catarina (SC). Este fluxo tornou SC um espaço onde se encontram, hoje, descendentes daqueles migrantes que estiveram no papel de colonizadores nos séculos passados, com os 'novos migrantes', ou seja, as populações racializadas que há menos de 200 anos ainda não tinham reconhecido seu status de 'civilizados', e que ainda hoje seguem ocupando lugares marginais na sociedade, e que são provenientes de nações que foram colonizadas. Facilitar esse encontro, a partir de uma perspectiva Decolonial e acolhedora para que os novos migrantes tenham reconhecida sua condição de Humanos e possam integrar-se plenamente neste país, é propósito central do Projeto de Extensão “Cátedra Sérgio Vieira de Mello: Núcleo de Apoio a Imigrantes e Refugiados”, criado em 2014 na Universidade Federal de Santa Catarina.

O Projeto surgiu, em especial, diante da inexistência de políticas estaduais específicas, o que incitou a UFSC e setores da sociedade civil a protagonizarem o acolhimento desses coletivos. A Cátedra é ação do "Eirenè: Centro de Pesquisas e Práticas Decoloniais e Pós-Coloniais aplicadas às Relações Internacionais e ao Direito Internacional", vinculado aos Cursos de Relações Internacionais e Direito. O Eirenè engloba atividades efetuadas em três pilares, nomeadamente, ensino, pesquisa e extensão.

3 “Desde 2005, a migração Sul-Sul tem crescido mais rápido que a migração Sul-Norte. O Sul abriga cerca de 84\% da população total do mundo e é a origem de cerca de $74 \%$ da migração internacional. Enquanto o número de migrantes Sul-Norte (originário do Sul, vivendo no Norte) tem aumentado cerca de 9 milhões a cada cinco anos desde 1990, o número de migrantes Sul-Sul permaneceu quase inalterado em cerca de 60 milhões entre 1990 e 2005 e depois aumentou rapidamente para mais de 105 milhões em 2019”. (UNITED NATIONS, 2019)

4 "São chamados novos imigrantes os contingentes que chegam desde meados da primeira década do século XXI. Ainda que os europeus portugueses e espanhóis, que chegaram por conta da crise econômica na Europa, não tenham ganho tanta visibilidade, também somam-se aos fluxos de ganeses, senegaleses, refugiados sírios, imigrantes de países do Mercosul e outros páses sul americanos (um movimento mais antigo em relação a esses fluxos)[...]" (GAIRF, 2015) 
"Mil nações moldaram minha cara": o Brasil, as migrações Sul-Sul e a extensão em Relações Internacionais

A extensão é o eixo do tripé institucional de contato direto com a comunidade. Assim, é por meio do diálogo com a/o outra/o que se pode viabilizar ações destinadas à construção coletiva de saberes e práxis pluriversitários, descolonizadores e emancipadores que estejam empenhados em transformar o mundo que nos perpassa. Pois, enquanto sujeitos sociais, devemos assumir responsabilidades históricas de transformar as estruturas que desumanizam as pessoas. Neste contexto, as práticas extensionistas do Eirenè são orientadas pelas epistemologias (anti) Pós e De-coloniais e, por isso, são baseadas na intercomunicabilidade, já que procuram promover o diálogo com o mundo, em lugar de apenas falar sobre ou para o mundo.

A Universidade deve invadir a rua e a rua deve invadir a Universidade. Por isso, a extensão é concebida como uma forma de descolonização da Universidade desde que se privilegie o encontro respeitoso e não hierarquizado com a diferença, em um exercício de escuta profunda e respeitosa das outridades. A Universidade, enquanto lugar de transformação, deve atuar sobre a realidade que nos mediatiza, e o nosso conhecimento deve ser atravessado pelo mundo (FREIRE, 1979).

Assim, o Projeto de Extensão opera no campo das migrações, desenvolve ações concretas com e para pessoas em situação de mobilidade internacional, e é orientado pelos seguintes princípios: a) intercomunicabilidade e promoção de diálogos não-hierarquizados com imigrantes, e com os parceiros da rede de ativismo sobre mobilidade humana; b) fomento de parcerias e atuação em rede; c) interconexão entre pesquisa, ensino e extensão; d) recurso a uma metodologia circular vocacionada a possibilitar a realização de encontros e práxis fora dos muros da Universidade mas, igualmente, a estimular as comunidades não-acadêmicas a interagirem com a academia, e a participarem de ações nas dependências da UFSC.

O objetivo deste texto é apresentar brevemente o projeto desenvolvido, para assim contribuir para o debate sobre extensão universitária, que ganha corpo nesse momento de reconstituir os laços entre ensino, pesquisa e extensão.

\section{MATERIAIS E MÉTODOS}

O Projeto de Extensão Cátedra Sérgio Vieira de Mello (doravante CSVM/Eirenè/UFSC) é uma ação internacional, pois é fruto de convênio assinado entre a UFSC e o Alto Comissariado das Nações Unidas para Refugiados (ACNUR/ONU). Assim, trata-se de uma Cátedra Internacional de Extensão que está em execução na UFSC desde o final de 2014. A Cátedra Sérgio Vieira de Mello é uma iniciativa do ACNUR e do Comitê Nacional para Refugiados (CONARE) e objetiva promover atividades de pesquisa e extensão sobre o Direito Internacional 
"Mil nações moldaram minha cara": o Brasil, as migrações Sul-Sul e a extensão em Relações Internacionais

dos Refugiados. Segundo o ACNUR, "ao longo dos anos, as Cátedras têm se revelado um ator fundamental para garantir que pessoas refugiadas e solicitantes de refúgio tenham acesso a direitos e serviços no Brasil, oferecendo valioso apoio ao processo de integração local”.

A CSVM/Eirenè/UFSC nasceu com o propósito de promover uma extensão intercomunicadora com imigrantes e com a rede de acolhimento local e estadual, com o fito de promover práticas e pesquisas vocacionadas a salvaguardar o direito humano de migrar e a transformar a realidade que nos mediatiza a partir do diálogo. A proposta é conduzida pela concepção freireana de extensão enquanto um encontro afetuoso e não-hierarquizado com a diferença destinado a construir soluções coletivas para desafios sociais (FREIRE, 1979).

O público-alvo do Projeto são imigrantes que residem em Florianópolis e grande região. Neste sentido, é relevante atestar que esta atuação extensionista é totalmente balizada pelo entendimento segundo o qual migrar é um direito humano que deve ser respeitado e garantido. Com base nisso, a CSVM/Eirenè/UFSC tem trabalhado nas seguintes frentes:

1) Atendimento diário a imigrantes e refugiados na Defensoria Pública da União (DPU), nas áreas de Direito Consular, Direito Internacional Humanitário e Direitos Humanos, com grande destaque para ações de acessibilidade documental (regularização migratória). A parceria entre a UFSC e a DPU se iniciou em 2016. O atendimento era realizado, também, e em maior escala, na Pastoral do Migrante entre os anos de 2015 a 2018. E, na sequência, com a criação do Centro de Referência de Atendimento ao Imigrante (CRAI) em fevereiro de 2018, a UFSC subscreveu acordo com a Associação Social Arquidiocesana (ASA) para atuação junto ao CRAI, e as atividades da CSVM/Eirenè/UFSC foram transladadas para essa instituição, e se mantiveram até setembro de 2019, quando o Centro de Referência fechou as portas devido à negativa de renovação do contrato por parte do governo de Santa Catarina.

Os números de atendimentos diários variaram durante os anos de 2015 a 2019. No início de 2015, a média era de 40 pessoas/dia na Pastoral do Migrante. A partir de maio de 2015, o número dobrou, e houve meses em que foram atendidas entre 80 a 100 pessoas/dia, em função, sobretudo, da chegada crescente de haitianos naquele período. Essas proporções alcançaram uma queda de 50\% a partir do segundo semestre de 2016, e se mantiveram estabilizadas até o início de 2018, quando os serviços passaram a ser prestados pelo CRAI. De fevereiro de 2018 a setembro de 2019, foram realizados 10.159 atendimentos e realizados 14.606 procedimentos, o que perfazia cerca de 30-40 atendimentos/dia. Com o fechamento do CRAI, atualmente na DPU ${ }^{5}$ estão sendo realizados aproximadamente 30 atendimentos diários.

$5 \mathrm{O}$ atendimento em parceria com a DPU ocorre na sede desta Instituição, situada na Rua Frei Evaristo, 142 Centro, Florianópolis. O horário de atendimento é de segunda a sexta, das $10 \mathrm{~h}$ às $16 \mathrm{~h}$. 
"Mil nações moldaram minha cara": o Brasil, as migrações Sul-Sul e a extensão em Relações Internacionais

2) Ações de advocacy propostas a demandar os poderes estatais a assegurarem direitos, e a formularem e implementarem políticas públicas efetivas de integração e acolhimento. Neste campo, as mobilizações são realizadas em vários fóruns, com destaque para dois que têm servido para impulsionarem o tema. O primeiro é o Grupo de Apoio a Imigrantes e Refugiados da região da Grande Florianópolis (GAIRF), constituído em 2014 por atores públicos e privados e com forte participação da sociedade civil. No grupo são promovidos debates e ações concretas para facilitar a integração de imigrantes na sociedade brasileira, reivindicando respostas do poder público para os temas migratórios em Santa Catarina. O segundo é o Grupo de Trabalho de Apoio aos Imigrantes e aos Refugiados (GTI) da Assembleia Legislativa do Estado de Santa Catarina. O GTI foi fundado em 2015, por iniciativa da Comissão de Direitos Humanos (CDH) da Assembleia Legislativa do Estado de Santa Catarina (ALESC). Trata-se de um colegiado onde o Legislativo, em parceria com a sociedade civil e diversas entidades, atua em conjunto com várias Instituições públicas e privadas, nomeadamente o Ministério das Relações Exteriores, o Ministério Público, a Secretaria de Estado da Educação, a Pastoral do Migrante, o GAIRF, a UFSC, a Círculos de Hospitalidade, associações de imigrantes, entre outras. Ou seja, trata-se de um espaço institucionalizado onde é possível formalizar as demandas levantadas no GAIRF, vindicar respostas do Executivo e do Judiciário e, quando possível, coordenar com o Legislativo a tomada de posturas e decisões ${ }^{6}$. Foram as ações de Advocacy coletiva dos diversos atores congregados no GAIRF e no GTI, incluindo o Eirenè/CSVM, que conseguiram articular a criação do CRAI, que foi o segundo Centro de Referência do Brasil, como política pública. Por fim, convém indicar que o Eirenè faz parte da Comissão da UFSC destinada a implementar vagas específicas para imigrantes e refugiados por meio de sistema de ações afirmativas (cotas). Por meio da Portaria 2245/2018/GR, publicada em 19 de outubro de 2018, a Secretaria de Ações Afirmativas da UFSC instituiu o Grupo de Trabalho encarregado de propor uma Política para Refugiados e Imigrantes com Visto Humanitário na Universidade Federal de Santa Catarina. Os trabalhos da Comissão ainda estão em andamento.

3) Intervenção social. Nesta frente destacam-se: as capacitações que têm sido ministradas para agentes públicos e para imigrantes; a elaboração de cartilhas e material informativo para agentes públicos e para imigrantes; a criação de banco de tradutores para atendimento a imigrantes em situações emergenciais, como ocorreu em 2015, quando dezessete ônibus vindos do Acre com pessoas haitianas e senegalesas chegaram a Santa Catarina e, a pedido

6 As reuniões do Grupo de Trabalho são realizadas ao menos uma vez por mês. 
"Mil nações moldaram minha cara": o Brasil, as migrações Sul-Sul e a extensão em Relações Internacionais

das Secretarias de Assistência Social do Município e do estado de SC, e em parceria com a Pastoral do Migrante, o Eirenè montou uma unidade de atendimento no estádio Saul Oliveira (Capoeirão) para prover a documentação dos recém-chegados ${ }^{7}$.

4) Monitoramento dos fluxos migratórios para Santa Catarina. A partir dos atendimentos efetuados diariamente pelos extensionistas, são geradas informações que são armazenadas em um banco de dados que, por sua vez, possibilita desenhar o perfil migratório catarinense com suas demandas. Estes dados são destinados a subsidiar as pesquisas do Eirenè, bem como as ações de advocacy que são utilizadas para reivindicar a formulação de políticas públicas. Desta forma, é importante observar que as pesquisas são alimentadas pela extensão e vice-versa. Durante este período de execução do projeto, vários artigos foram publicados em revistas e livros nacionais e internacionais que publicizam tais dados estatísticos ${ }^{8}$.

5) Associação pesquisa-ensino-extensão. Neste momento da Universidade brasileira, quando estamos envoltos na tentativa de entender o que significa, de fato e no concreto, “associar" o ensino à extensão e à pesquisa, nós do Eirenè supomos que essa compreensão virá com a ação, com a praxis. Por esse motivo temos nos empenhado, juntamente com a Coordenação do Curso de Relações Internacionais, para identificar as habilidades cognitivas e os conteúdos desenvolvidos por meio das atividades de extensão, incorporando-os de forma orgânica ao currículo do curso. Nesse processo, buscamos também nos articular com outros Núcleos que realizam ações convergentes. Exemplos são os núcleos que trabalham no campo da mobilidade humana e laboram de forma coordenada com a CSVM, nomeadamente: o Projeto de Extensão "Português como língua de acolhimento" (PLAM), promovido pelo Núcleo de Pesquisa e Ensino de Português - Língua Estrangeira (NUPLE), que oferece aulas gratuitas de português para imigrantes e refugiados da Grande Florianópolis; o Projeto "Direito à cidade para imigrantes e refugiados na Grande Florianópolis: integração aos serviços públicos e de lazer" do Curso de Geografia; e o Núcleo de Estudos sobre Psicologia, Migrações e Culturas (NEMPsiC). O PLAM e o NEMPsiC também aderiram à CSVM/UFSC.

Ainda no contexto do processo de curricularização da extensão, foi criada, em caráter pioneiro, a disciplina optativa intitulada “Tópicos: Extensão em Migrações e Refúgios” no Curso

7 Consultar: https://irene.ufsc.br/2019/11/18/tbt-eirene-memoria-da-participacao-do-eirene-no-mutirao-parareceber-os-onibus-de-imigrantes-haitianos-chegados-em-florianopolis-em-2015/; campanhas de arrecadação de roupas e alimentos para pessoas em situação de vulnerabilidade. Essas ações podem ser consultadas na página do Eirenè (www.irene.ufsc.br)

8 As publicações encontram-se registradas na Plataforma Lattes e estão, igualmente, compartilhadas no sítio do Eirenè. 
"Mil nações moldaram minha cara": o Brasil, as migrações Sul-Sul e a extensão em Relações Internacionais

de Relações Internacionais, tendo sido ofertada pela primeira vez no segundo semestre de 2018. Tratou-se de uma disciplina-piloto que integrou tridimensionalmente o ensino e a pesquisa, a partir da extensão?. A disciplina possibilitou a concretização de várias rodas de conversas, ocorridas em espaços de dentro e de fora da UFSC, com imigrantes de diversas nacionalidades, e com entidades que atuam na militância estadual e nacional, a saber: Pastoral do Migrante, Cáritas, Polícia Rodoviária Federal, Ministério das Relações Exteriores, as ONGs "Círculos de Hospitalidade" e "Associação Brasileira de Defesa da Mulher da Infância e da Juventude" (ASBRAD). Além disso, foram desenvolvidas atividades extra-classe em parceria com o CRAI, com a Pastoral do Migrante, a Cáritas, o GAIRF e GT da ALESC.

Uma das atividades obrigatórias da cadeira, e que merece destaque neste relato, foi desenvolvida em associação com o Projeto de Extensão NUPLE, ou seja, garantiu a interdepartamentalidade da extensão na UFSC. Durante algumas semanas do semestre, os/as estudantes da disciplina apoiavam os/as professores/as do PLAM em suas aulas. Nos encontros, eram apresentadas as cartilhas e folders que haviam sido produzidas anteriormente pela CSVM/Eirenè e parceiros, e realizadas dinâmicas teatrais e de conversação em grupos e duplas para fixação dos temas aprendidos. Tal ferramenta pedagógica foi muito produtiva, e pode ofertar pistas para a curricularização da extensão envolvendo diferentes cursos.

Conforme explicitado anteriormente, um dos princípios da atuação extensionista da CSVM/Eirenè é a ação coordenada com parceiros destinada ao fortalecimento da rede de ativismo em mobilidade humana em Santa Catarina. Esta opção metodológica está afinada com os Objetivos de Desenvolvimento Sustentável (ODS) da ONU, entre os quais, o de número 17, que insta os Estados-membros a entabularem parcerias para implementação da Agenda 2030, e o $n^{\circ} 10$ que estipula a obrigação de implementação de políticas públicas de imigração e refúgio. Assim, os Estados devem facilitar "a migração e a mobilidade ordenada, segura, regular e responsável das pessoas, inclusive por meio da implementação de políticas de migração planejadas e bem geridas" (Agenda 2030, ONU). Com este panorama em vista, ao longo do quinquênio, muitas parcerias foram firmadas, entre as quais se destacam: com o ACNUR (que possibilitou a implementação da CSVM/UFSC), a DPU, a Ação Social Arquidiocesana (CRAI), a Pastoral do Migrante, e ONGs como a Círculos de Hospitalidades.

Por fim, observa-se que desde 2014, dezenas de estudantes da graduação e da pósgraduação em Direito e Relações Internacionais atuaram como extensionistas, além de intercambistas do University Studies Abroad Consortium (USAC/UFSC). Nota-se, também, a

9 O número de matriculados foi de 23 discentes vindos dos Cursos de Relações Internacionais, Direito, Economia, Arquitetura, Engenharia de Alimentos, Geografia, além de duas intercambistas, uma dos Estados Unidos e outra da Espanha, e uma estudante de mobilidade nacional, da Universidade Federal do Rio Grande. 
"Mil nações moldaram minha cara": o Brasil, as migrações Sul-Sul e a extensão em Relações Internacionais

participação de discentes de outros cursos de graduação da UFSC, e de outras IES nas ações de intervenção social e nos eventos.

\section{RESULTADOS E ANÁLISES}

As ações de extensão desenvolvidas pelo Eirenè/CSVM/UFSC, juntamente com seus parceiros da rede de militância municipal e estadual, têm demonstrado notado impacto social, e têm se revelado extremamente úteis para a formulação de políticas públicas de acolhimento e integração conforme disposto no artigo 120 da Lei de Migração.

Dentre os principais resultados, destaca-se a inauguração do CRAI-SC enquanto política pública - um importante fruto da militância de diversos atores no GTI e no GAIRF, incluindo a participação ativa do Eirenè/CSVM. A Ação Social Arquidiocesana venceu a licitação constante no Edital de Concorrência Pública n ${ }^{\circ}$ 0028/2016, para implementar o CRAI-SC. O Centro de Referência, que funcionou de fevereiro de 2018 a setembro de 2019, foi o primeiro da região Sul e foi resultado de um convênio celebrado entre a União, o estado de SC e a ASA. A UFSC, por sua vez, firmou convênio com a ASA para realização das atividades de Extensão na Pastoral do Migrante e no CRAI. É relevante sublinhar que as informações coletadas e registradas nos cadastros de migrantes, bem como o conhecimento construído durante o trabalho na Pastoral e, posteriormente, no CRAI, foram fundamentais para subsidiar a construção de uma política estadual para essa população. Nesses dois espaços de atendimento - Pastoral do Migrante e o CRAI - foram realizados cerca de 30 mil atendimentos - atingindo uma média de 6 mil por ano a imigrantes e refugiados de 62 nacionalidades, residentes em 36 cidades de Santa Catarina, em dois municípios do Rio Grande do Sul e um do Paraná, conforme tabelas 1 e 2 abaixo. Os dados coletados revelam, também, que a maioria significativa das pessoas acolhidas é racializada e proveniente de países do Sul Global. Estas são, também, as que são as mais vulnerabilizadas diante da inexistência de políticas públicas interseccionais de acolhimento e integração. Importante observar que imigrantes negros são vulnerabilizados pela inação do Estado. Ou seja, não são pessoas vulneráveis; são pessoas vulnerabilizadas devido à inexistência de políticas públicas, o que é diferente.

Tabela 1

\section{Nacionalidades/ Países}

Alemanha, Angola, Argentina, Benin, Bolívia, Cabo Verde, Camarões, Cazaquistão, Chile, China, Colômbia, Costa Rica, Cuba, Guiana, Egito, Equador, Espanha, Estados Unidos, França, Filipinas, Gana, Guiné, Guiné Bissau, Haiti, Honduras, Hungria, Iêmen, Ilhas Salomão, Ilhas Comores, Inglaterra, Irã, Israel, Itália, Kuwait, Libéria, Líbia, Mali, Marrocos, México, Moçambique, Namíbia, Nigéria, Nova Zelândia, Palestina, Paquistão, Paraguai, Peru, Portugal, 
"Mil nações moldaram minha cara": o Brasil, as migrações Sul-Sul e a extensão em Relações Internacionais

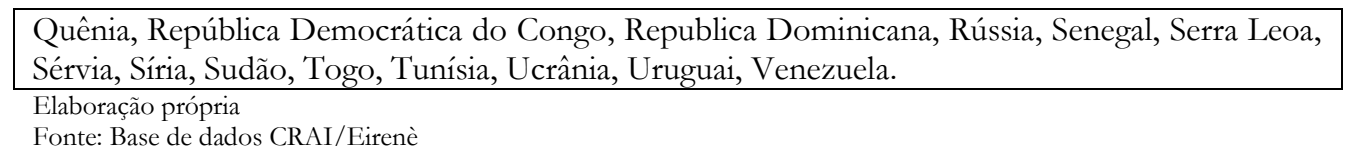

Tabela 2

\begin{tabular}{|l|l|}
\hline Cidades de Residência de Imigrantes & Unidade da Federação \\
\hline Antônio Carlos, Balneário Camboriú, Biguaçu, Blumenau, Bombinhas, & Santa Catarina \\
Camboriú, Canelinha, Brusque, Capinzal, Chapecó, Concórdia, & \\
Criciúma, Florianópolis, Garopaba, Gaspar, Governador Celso Ramos, & \\
Imbituba, Indaial, Itajaí, Itapema, Jaraguá do Sul, Joinville, Lages, & \\
Laguna, Navegantes, Palhoça, Rio do Sul, Santo Amaro da Imperatriz, & \\
São Bonifácio, São Joaquim, São João Batista, São José, São Pedro de & \\
Alcântara, Tijucas, Tubarão, Urubici. & Paraná \\
\hline Curitiba & Rio Grande do Sul \\
\hline Porto Alegre, Vacaria & \\
\hline Elaboração própria & \\
Fonte: Base de dados CRAI/Eirenè &
\end{tabular}

Dispensável dizer que os resultados das pesquisas foram publicados em revistas científicas de circulação nacional. Mais do que isso, ao sair-se de si em direção ao mundo, o conhecimento da Universidade ganhou corpo e tornou-se realidade, contribuindo para transformar a sociedade em direção àquilo que defendíamos em sala de aula - direito à igualdade e à existência digna. Para isso as parcerias com a comunidade foram indispensáveis.

O Eirenè apoiou o CRAI no estabelecimento de parcerias com o SENAC Florianópolis (Unidade Prainha) e com o IGEOF para capacitação de imigrantes, promovendo ações de fomento à geração de renda e empreendedorismo como a Feira Gastronômica e artística do imigrante. Esta ação coordenada por coletivos de imigrantes continua hoje de forma relativamente autônoma: a feira ocorre desde dezembro de 2017 e atualmente é estabelecida uma vez por semana no Centro de Florianópolis. Para que a feira ocorra, o CRAI/Eirenè se responsabilizaram pela divulgação; o IGEOF pela emissão de alvará; e imigrantes coordenam a exposição. Mais de quarenta imigrantes de dez diferentes nacionalidades já participaram do projeto desde a sua criação.

Esse é um ponto importante a destacar da extensão: o pensamento crítico e teórico da aula, ao incorporar-se nos sujeitos e ao guiar a ação, muda concretamente o mundo. Assim, o que ontem era sonho, utopia ou ideal, realiza-se, através obviamente de uma batalha com as circunstâncias. E o "mudar do mundo" significa transformar sujeitos passivos em cidadãos/as, capazes de reproduzir e multiplicar práticas transformadoras para a sociedade. A extensão, ao construir conhecimento, acende o pavio, mas não precisa sempre trabalhar para alimentar o fogo.

Com essa diretriz em vista, o Eirenè/CSVM - em parceria com a Pastoral do Migrante ministrou oficina de formação para profissionais da área de saúde e elaborou com a colaboração de um médico da rede municipal de Saúde de Florianópolis, o folder "Atendimento médico a 
"Mil nações moldaram minha cara": o Brasil, as migrações Sul-Sul e a extensão em Relações Internacionais

Migrantes", contendo sintomas e doenças crônicas, com o intuito de facilitar a expressão de problemas e sintomas que podem ser resolvidos por atendimento médico. A ação contou com apoio da Secretaria de Saúde Municipal. O folder possui versão em cinco idiomas: Árabe, Creole Haitiano, Espanhol e Francês e Inglês e pode ser acessado no site do Eirenè ${ }^{10}$.

Com a finalidade de expandir o conhecimento adquirido por todos que fazem parte da CSVM, e facilitar o atendimento aos imigrantes e refugiados por outros órgãos que não estavam acostumados com a grande demanda recém-chegada na Grande Florianópolis, o Eirenè/CSVM elaborou uma cartilha, "BEM-VINDOS A SANTA CATARINA: um guia para refugiados e imigrantes". A cartilha ${ }^{11}$ destina-se também a imigrantes e refugiados para que possam conhecer seus direitos e ter acesso a informações sobre regularização migratória, saúde, educação, sobre questões práticas relacionadas à locomoção na cidade por meio de transporte público.

Ações sociais também foram executadas, como as diversas campanhas para arrecadação de roupas, alimentos e material escolar. Nessa esteira, ressalta-se o recebimento de doação de uma tonelada de alimentos feita pelos cantores Emicida e Criolo, em 2016, para ser entregue a migrantes e refugiados (http://irene.ufsc.br/2017/02/06/eirene-agradece-aos-cantores-criolo-eemicida/).

Em 2019, foi realizada a "Campanha Natal sem Fronteiras", organizada pelo Eirenè com o apoio do PLAM. Tratou-se de uma ação que estimulou crianças a escreverem cartinhas a Papai Noel com um pedido de presente. Cinquenta e oito crianças de seis nacionalidades enviaram cartas, sendo que as professoras do PLAM ajudaram a muitos pais e mães imigrantes a escreverem as cartas nas aulas de português. Pessoas da UFSC e da comunidade adotaram as cartas e a festa de entrega dos presentes ocorreu no dia 23 de novembro.

Conforme mencionado supra, foi, também, criado um banco de tradutores para atendimento a imigrantes em situações emergenciais. Cerca de 200 tradutores se inscreveram e muitos atuaram em 2015, no atendimento aos dezessete ônibus com imigrantes vindos do Acre que vieram para Santa Catarina. O Eirenè esteve em vigília entre a última semana de maio até a primeira semana de junho, período da chegada dos ônibus.

Por último é relevante ressaltar a participação ativa da CSVM na elaboração do Projeto de Lei (PL) estadual que institui uma Política para Imigrantes em Santa Catarina. Durante um ano, o GT debateu os termos da proposta. A professora Karine de Souza Silva foi responsável por incluir no PL o combate ao racismo, a menção às ações afirmativas para imigrantes negros e materiais-de-campanhas/.

11 Cartilha disponível através do link: http://irene.ufsc.br/2016/09/08/publicacao-da-cartilhabem-vindo-a-santa-catarina-um-guia-para-refugiados-e-imigrantes/. 
"Mil nações moldaram minha cara": o Brasil, as migrações Sul-Sul e a extensão em Relações Internacionais

negras, e a necessidade de abordagem interseccional para combater as opressões de gênero, raça, etnia e sexualidades.

\section{CONSIDERAÇÕES FINAIS}

A extensão tem o poder de transformação. Transformação é o termo que mantém de pé o conceito utilizado nas Políticas Públicas para a área da educação no Brasil. Assim, sendo parte do serviço público brasileiro, entendemos que nossas práticas como educadores devem se orientar para transformar a sociedade que hoje temos pactuada pela Constituição Federal de 1988. E, como bons educadores, sabemos que só é possível cumprir o dever de cidadã/x-educador/x quem entende o que é transformação. Assim como não sabe o que é maçã quem nunca a experimentou, também não sabe o que é transformação quem nunca a vivenciou. Por isso, é necessário fazer extensão para realizarmos, enquanto Universidade, o princípio da Igualdade, que foi inscrito na Constituição não porque somos iguais, mas porque julgamos, como nação, que esse ideal tão alto ainda está tão distante.

O Brasil, país conhecido como "pátria de migrações" por ter sido formado por várias nações, etnias e raças, não sabe encontrar-se com a alteridade. Relaciona-se com os/as que julga que são semelhantes a si, com aqueles/as que lhe inspiram os sonhos, que lhe povoam memórias e mitos de glória, mas deprecia aqueles/as que foram racializados, aqueles/as cujos ascendentes, na historiografia oficial, não figuram senão como escória, como serviçais. No geral, neste Estado da fábula da democracia racial não se concede aos corpos negros o direito à existência digna. Pergunte-se, leitor/a/x: qual foi o último sentimento de afeto não hierarquizado - que não seja pena - que desenvolveu por alguém de outra cor? Ou com renda muito distinta? Ou por quem não sabe ler? Ou por quem mora sem um teto em cima? Há solidariedade, há sentimento de nação, dentro das classes, e dentro das raças, mas não fora delas.

Por isso a migração para o Brasil de países do "Sul" ainda é um tabu. Enfrentá-lo é completar a tarefa da descolonização, que significa, também, completar a marcha pela igualdade da Constituição, e construir uma nação. É transformar o mundo - ou melhor, as pessoas do mundo - para que possamos receber em nossa casa, com o mesmo afeto e cuidado, tanto aqueles que nasceram na metrópole como na colônia. Por isso, o projeto do Eirenè, por isso a extensão.

\section{REFERÊNCIAS}

ACNUR. Cátedra Sérgio Vieira de Mello. Disponível em: https://www.acnur.org/portugues/catedra-sergio-vieira-de-mello/. Acesso em 05 dez 2019. 
"Mil nações moldaram minha cara": o Brasil, as migrações Sul-Sul e a extensão em Relações Internacionais

FREIRE, Paulo. Extensão ou comunicação? Trad. de Rosisca Darcy de Oliveira. 8 ed. Rio de Janeiro, Paz e Terra, 1985.

GAIRF (Grupo de Apoio ao Imigrante e Refugiado de Florianópolis e Região). Novos Imigrantes e Refugiados na Região da Grande Florianópolis: Observaçóos preliminares sobre suas experiências e demandas. Florianópolis, 2015. Disponível em: https://imigrafloripa.files.wordpress.com/2015/08/relatc3b3rio-gairf-versao-publicar-ult.pdf Acesso em 13 nov 2019.

SILVA, Karine de Souza; MULLER, Juliana; SILVEIRA, Henrique Martins da. Santa Catarina no roteiro das diásporas: os novos imigrantes africanos em Florianópolis. Revista Katálysis, Florianópolis, v. 21, n. 2, p.281-292, ago. 2018. Disponível em: https://periodicos.ufsc.br/index.php/katalysis/article/view/1982-02592018v21n2p281/36972 . Acesso em: 31 mar. 2019.

SILVA, Karine; GESTAL, Emanuely. Santa Catarina na rota das migrações: a atuação do Núcleo de Apoio a Imigrantes e Refugiados da Universidade Federal de Santa Catarina. In: ANNONI, Danielle. (Org.). Direito Internacional dos refugiados e o Brasil. 1ed.Curitiba: UFPR, 2018, v. 1, p. 536-555.

UNITED NATIONS. Population Facts September 2019 | No. 2019/4, p. 3. Disponível em: https://www.un.org/en/development/desa/population/migration/publications/populationfacts Ldocs/MigrationStock2019 PopFacts 2019-04.pdf Acesso em 14 novembro 2019.

Recebido em: 26/11/2019

Aceito em: $12 / 12 / 2019$ 